\title{
Commentary: Can a part be as good as the whole?
}

\author{
Ross M. Bremner, MD, PhD
}

\author{
From Norton Thoracic Institute, St Joseph's Hospital and Medical Center, Phoenix, Ariz. \\ Disclosures: Author has nothing to disclose with regard to commercial support. \\ Received for publication Aug 19, 2019; accepted for publication Aug 19, 2019; available ahead of print Oct 21, \\ 2019. \\ Address for reprints: Ross M. Bremner, MD, PhD, Norton Thoracic Institute, St Joseph's Hospital and Medical \\ Center, 500 W. Thomas Rd, Ste. 500; Phoenix, AZ 85013 (E-mail: Ross.Bremner@ DignityHealth.org). \\ J Thorac Cardiovasc Surg 2020;159:e93-4 \\ 0022-5223/ $\$ 36.00$ \\ Copyright (c) 2019 by The American Association for Thoracic Surgery \\ https://doi.org/10.1016/j.jtcvs.2019.08.091
}

Transplantation of 2 bilateral lower-lung lobes from 2 separate living donors was developed out of necessity in the era of long transplant waitlist times and high waitlist mortality. ${ }^{1}$ Many young patients' lives were certainly saved with the living-donor lobar approach, but in the United States the use of that operation has declined since the introduction of the new Lung Allocation Scoring system. That system has resulted in the availability of more cadaveric organs for more critically ill patients and avoids the associated morbidity (and potential mortality) to healthy donors undergoing a thoracotomy and lobectomy. The surgical procedure for a living-donor transplant is challenging, with very little room for error on both the donor and recipient sides.

Living-donor lobar lung transplantation is more common in countries in which cadaveric donor options are complicated, such as Japan. Laws in Japan have historically restricted the use of cadaveric organs, and donation after cardiac death is not a legal option. The living-donor lobar operation has therefore played a major role in transplantation in this country, accounting for almost $40 \%$ of Japan's total lung transplant volume. ${ }^{2}$

Living-donor lung transplantation has unique challenges compared with cadaveric transplantation, as the donated lobe is usually smaller than the thoracic cavity of the recipient and the shape of the lobe does not conform to the entire space. Pleural space issues are unique, as is the immunologic response of the recipient to organs from 2 separate donors. In the current paper by Nakajima et al, ${ }^{3}$ the authors, from one of the largest living-donor programs in Japan, have shown that the function of these lobes in their experience is equivalent to that of a whole bilateral cadaveric lung. Although this may seem surprising, it is in keeping with a previous report from the United States. ${ }^{4}$ In the current study, the spirometric parameters for cadaveric transplant are lower than expected when compared with volumetric data from the donor. This may be related to the fact that the majority of bilateral lung transplant recipients in Japan suffer from restrictive lung disease, bilateral lung transplant recipients are usually younger than 55 years old, ${ }^{2}$ and patients undergoing transplant for chronic obstructive pulmonary disease/emphysema is unusual in Japan. The confined chest

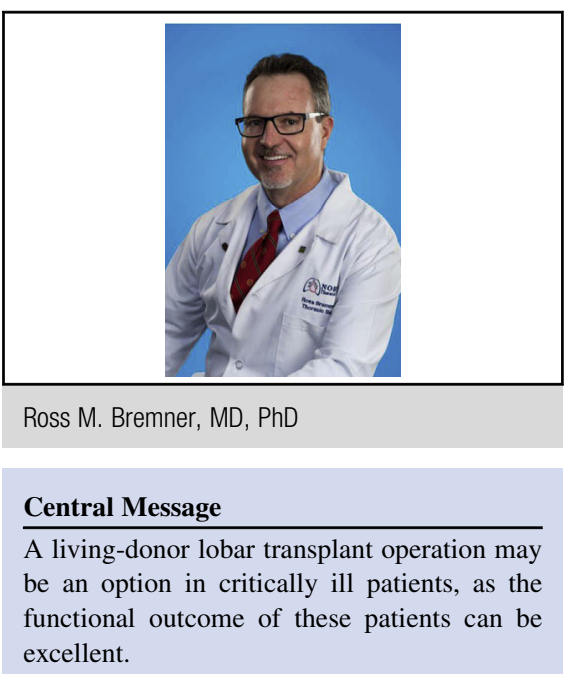

See Article page e87.

cavity in patients with restrictive lung disease and the incomplete expansion and function of the entire donor lung may account for this "less-than-perfect" function of the whole donor lung, as mentioned in the manuscript. Superior early function and decreased primary graft dysfunction can also be expected in the lobar experience. This is because donor lobes essentially have little to no ischemic time, as they can be removed from the donor, flushed, and immediately implanted in the recipient in the adjacent surgical suite.

The authors are to be applauded on their superb outcomes using this technique (despite these lobar patients being sicker and on greater-dose steroids at the time of transplant) but are also to be congratulated for the impressive 5-year survival of all patients (recipients of both living-donor and cadaveric organs). And although my experience has taught me that "a part is not quite as good as a whole," in this Japanese experience the functional outcomes are similar. This manuscript reinforces the need to keep the living-donor lobar transplant operation as an option in critically ill patients, as the functional outcome of these patients can be excellent.

\section{References}

1. Starnes VA, Barr ML, Cohen RG, Hagen JA, Wells WJ, Horn MV, et al. Livingdonor lobar lung transplantation experience: intermediate results. J Thorac Cardiovasc Surg. 1996;112:1284-90; discussion 1290-1.

2. Date H. Current status and problems of lung transplantation in Japan. J Thorac Dis. 2016;8(suppl 8):S631-6. 
3. Nakajima D, Chen-Yoshikawa TF, Ohsumi A, Date H. Living-donor lobar lung transplants provide comparable pulmonary function to cadaveric lung transplants. J Thorac Cardiovasc Surg. 2020;159:e87-90.
4. Bowdish ME, Pessotto R, Barbers RG, Schenkel FA, Starnes VA, Barr ML. Longterm pulmonary function after living-donor lobar lung transplantation in adults. Ann Thorac Surg. 2005;79:418-25. 